\title{
Long-Lasting Changes in Morphine Sensitivity Following Amygdaloid Kindling in Mice
}

\author{
ALFRED MANSOUR, RICHARD DOYLE, RICHARD KATZ AND ELLIOT S. VALENSTEIN ${ }^{1}$ \\ Psychology Department, Neuroscience Laboratory and Mental Health Research Institute \\ University of Michigan, Ann Arbor, MI 48109
}

Received 1 August 1981

\begin{abstract}
MANSOUR, A., R. DOYLE, R. KATZ AND E. S. VALENSTEIN. Long-lasting changes in morphine sensitivity following amygdaloid kindling in mice. PHYSIOL. BEHAV. 27(6) 1117-1120, 1981.-Mice tested at either 3, 27 or 90 days following their last amygdala kindled convulsion exhibited a marked increase in response to morphine compared to controls. Kindled animals showed a higher incidence of clonic convulsions and an exaggerated Straub tail response, both of which could be blocked by naloxone pretreatment. The changes in response to morphine produced by kindling may provide a model for studying the long-lasting effects of convulsions.
\end{abstract}

Kindling Amygdala Morphine Seizures Mice Convulsion Straub tail response

KINDLING refers to the gradual development of electrical discharges and behavioral convulsions in response to a regimen of brief, intermittent electrical stimulation of the amygdala and other brain structures [19]. The demonstration that kindling can induce a permanent seizure propensity in animals has raised the possibility that this technique may provide a tool for studying the brain mechanisms that underlie the long-lasting behavioral changes claimed to be produced by temporal lobe seizures. In addition to increasing seizure propensity, amygdala kindling has also been reported to produce persistent changes in predatory behavior [1], emotionality [32], and some types of learning [28].

In pursuing our interest in the mechanism that may underlie interictal changes in behavior, we have been influenced by several lines of evidence suggesting a relationship between opiate systems in the brain and seizure activity. Intraventricular injections of endogenous opiates have been shown, for example, to produce epileptiform activity $[16,17]$ and electroconvulsive shock (ECS) in rats produces "opiate-like" effects such as elevation of pain thresholds, catalepsy, and hypothermia [4] and all of these effects can be blocked by the opiate antagonist, naloxone. Repeated ECS has also been shown to increase sensitivity to opiates [3] and to elevate met-enkephalin levels in the hippocampus [22]. These reports of increased endogenous opiates following a regimen of convulsions may be relevant to the finding that kindling reduces morphine withdrawal symptoms in rats [25].

In addition, the amygdala, which is most sensitive to kindling [19], has one of the highest concentrations of opiate receptors in the brain [38]. Micro-injections of morphine into the amygdala produce seizures [39] while systemic morphine has been reported to induce electroencephalographic spiking in this structure [8]. The precise role of opiates in kindling, however, remains unclear. Morphine potentiates amygdala kindled seizures and increases the frequency of interictal spiking in kindled rats [24], but naloxone has been reported not to inhibit amygdala or caudate kindling $[11,34]$ and may even potentiate the rate of kindling [20].

To date, most studies have only examined the direct effects of opiates and opiate antagonists on kindling or the short-term changes in opiate systems following convulsions in rats. We report here that $\mathrm{C57BL} / 6 \mathrm{~J}$ mice exhibit a marked increase in morphine sensitivity following kindling that is detectable up to three months following an animal's last kindled convulsion.

\section{METHOD}

Adult C57BL/6J mice (Jackson Laboratories, Bar Harbor, ME) were implanted with bipolar electrodes in the amygdala. With the skull level, the stereotaxic coordinates were $1.7 \mathrm{~mm}$ posterior to bregma, $3.6 \mathrm{~mm}$ lateral, and 5.2 $\mathrm{mm}$ below the dorsal surface of the skull. The elctrodes consisted of two twisted teflon coated stainless steel wires $\mathbf{( 0 . 0 0 6}$ in dia.) soldered to microminiature pins (Winchester Co. 8456). An additional pin attached to a skull screw was placed anterior to the coronal suture and served as a ground for EEG recording.

Following recovery from surgery, the animals were divided into three experimental and three control groups. Twenty-five experimental animals were stimulated once

'Send reprint requests to Dr. Elliot S. Valenstein, Neuroscience Lab Building, 1103 E. Huron, University of Michigan, Ann Arbor, MI 48109. 


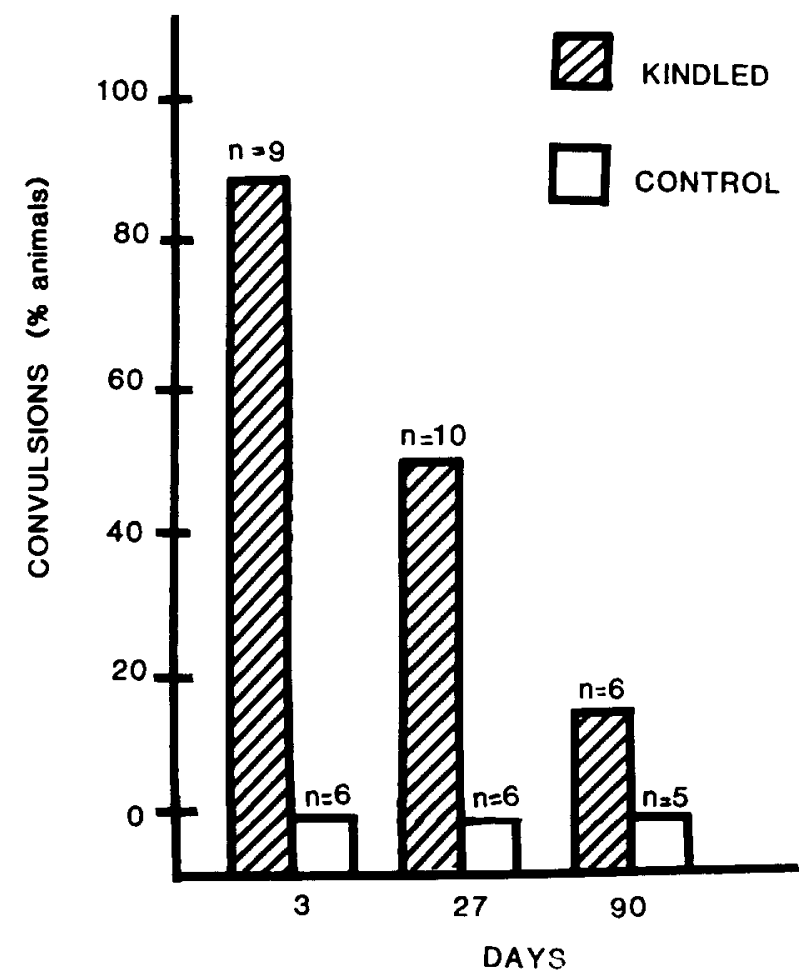

FIG. 1. Percentage of mice exhibiting clonic convulsions in response to morphine ( $25 \mathrm{mg} / \mathrm{kg} \mathrm{IP})$ at 3,27 , and 90 days after termination of kindling. Control mice were not kindled.

daily (4-7 hrs into the $12 \mathrm{hr}$ day cycle) with a $1 \mathrm{sec}$ duration, $50 \mu \mathrm{A}, 60 \mathrm{~Hz}$ sine wave current. Kindled convulsions were rated on a modified Racine scale [36] as follows: $1=$ mouth movements, 2 =head bobbing, $3=$ clonus, $4=$ generalized convulsions $(\mathrm{GC})$ plus rearing, $5=\mathrm{GC}$ plus rearing and falling, $6=\mathrm{GC}$ plus repeated rearing and falling, $7=\mathrm{GC}$ plus repeated rearing and falling followed by running.

The mice received daily stimulation until they reached a criterion of seven consecutive generalized convulsions (stages 5-7). Typically, mice had the first generalized convulsion after 13-14 stimulations and reached the criterion on approximately the 21 st stimulation day. After the animals had reached the criterion, they were injected with morphine $(25 \mathrm{mg} / \mathrm{kg} \mathrm{IP})$ at either 3 days $(\mathrm{N}=9), 27$ days $(\mathrm{N}=10)$ or 90 days $(\mathrm{N}=6)$ following their last kindled convulsion. Seventeen additional mice made up the three groups of unstimulated controls. These animals were implanted with amygdala electrodes, handled identically to the kindled animals (including time in the test chamber connected to the electrode cables), and tested with morphine at the 3,27, and 90 day intervals.

The occurrence of convulsions was recorded during the morphine test session. Animals were placed in Plexiglas boxes $(23 \times 23 \times 30 \mathrm{~cm})$ and observed continuously for the occurrence of convulsions over a $105 \mathrm{~min}$ period following the injection of morphine. An additional group of 7 mice were kindled to the same criterion and 3 days after their last convulsion they were pretreated with naloxone $(5 \mathrm{mg} / \mathrm{kg} \mathrm{IP})$

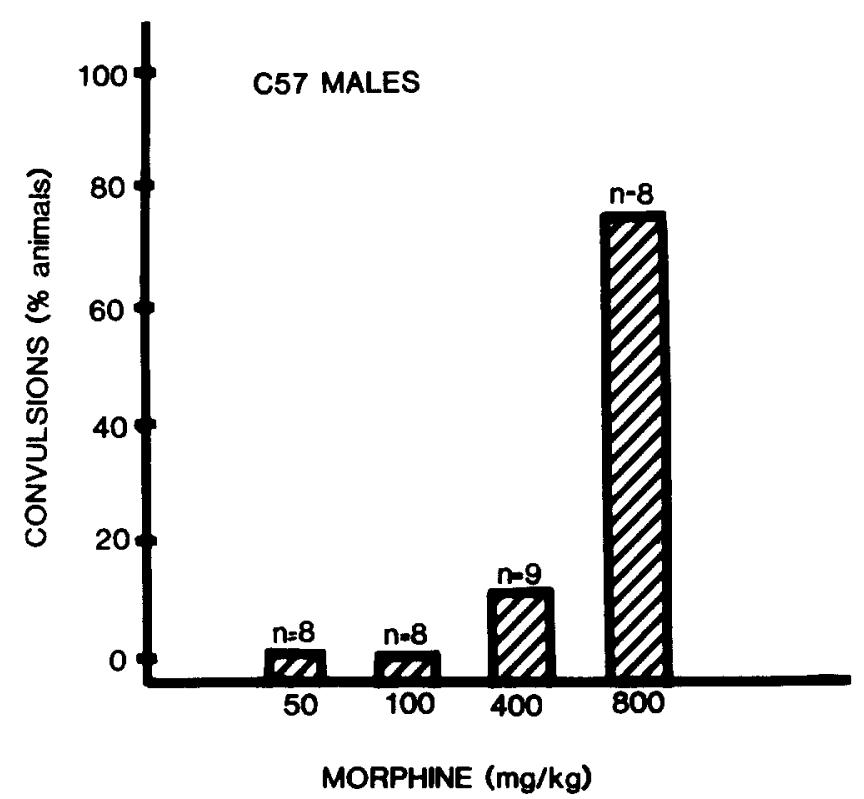

FIG. 2. Percentage of naive $\mathrm{C} 57$ mice showing tonic convulsions following different doses of morphine.

5 mintes prior to the administration of morphine $(25 \mathrm{mg} / \mathrm{kg}$ IP).

Following the termination of the experiment all the animals were anesthetized and perfused through the heart with saline and $10 \%$ Formalin. The brains were sectioned (40 $\mu \mathrm{m})$ and stained with cresyl violet to verify the electrode placements. The data presented here represent animals whose electrode tips were localized in the amygdaloid complex.

\section{RESULTS}

The kindled animals showed a high incidence of clonic convulsions following morphine (Fig. 1). The convulsions were behaviorally similar to those produced by electrical kindling and generally first occurred 25-35 min after the drug injection. Many of the animals had several convulsions. The incidence of morphine induced convulsions was highest in the 3 day group ( $89 \%$ ) and progressively declined in the 27 $(50 \%)$ and 90 day (16\%) groups. In marked contrast, none of the control animals $(\mathrm{N}=17)$ had a clonic convulsion following morphine.

In order to determine the extent to which amygdala kindling had increased morphine sensitivity, we treated separate groups of naive male C57 mice with $50,100,400$, and 800 $\mathrm{mg} / \mathrm{kg}$ doses of morphine and recorded the incidence of clonic convulsions. None of the naive mice convulsed at doses of $100 \mathrm{mg} / \mathrm{kg}$ or lower and only $11 \%$ (1 of 9) convulsed following a $400 \mathrm{mg} / \mathrm{kg}$ dose of morphine. Although the majority $(88 \%)$ of the animals did convulse and die at a dose of $800 \mathrm{mg} / \mathrm{kg}$ (Fig. 2), none of the animals displayed the clonic convulsion typical of kindled animals injected with much lower doses of morphine. The convulsions of the naive animals were tonic in nature and occurred at the time the animals expired from respiratory failure. 


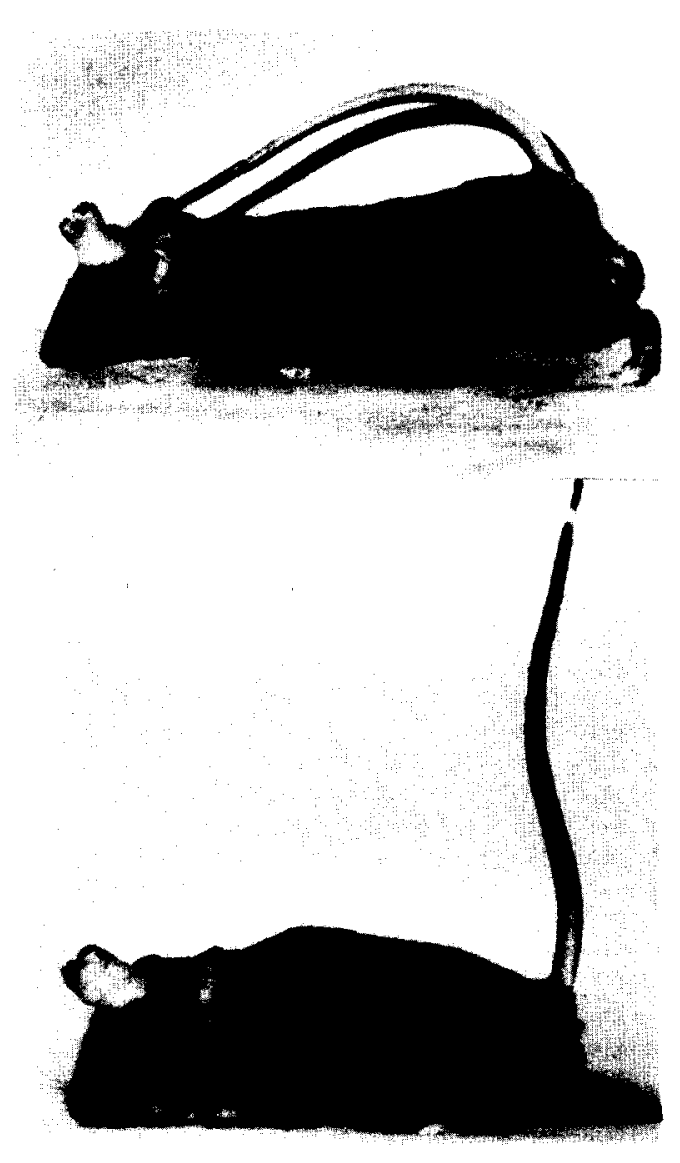

FIG. 3. Straub tail response of kindled (top) and control (bottom) mice given morphine ( $25 \mathrm{mg} / \mathrm{kg}$ IP) 3 days following the termination of kindling.

In addition to a high incidence of convulsion, kindled animals showed a very exaggerated Straub tail response compared to controls. When injected with morphine, the stiffened tails of the kindled mice typically extended forward in an arch to the top of the animal's heads. In contrast, the tails of control animals given morphine rarely extended beyond a vertical position (Fig. 3).

Naloxone pretreatment blocked the morphine induced convulsions in 6 of the 7 kindled mice and attenuated the Straub-tail response. These results are clearly different from those obtained with the 3-day group given morphine alone where 8 of 9 animals had convulsions.

\section{DISCUSSION}

The results clearly indicate that kindling produces a longlasting increase in morphine sensitivity. The increase in morphine sensitivity in kindled mice is reflected in the significant increase in clonic convulsions and Straub tail response induced by this drug. The magnitude of this effect is demonstrated by the fact that normal C57 mice do not display clonic convulsions in response to morphine even in lethal doses, and also by recent work in our laboratory demonstrating that doses as low as $10 \mathrm{mg} / \mathrm{kg}$ elicit clonic convulsions in $40 \%$ of kindled C57 mice. It should be noted in this context, that a dose of $10 \mathrm{mg} / \mathrm{kg}$ morphine produces only a mild analgesia in normal C57 mice [6].The ability of naloxone to block the heightened response to morphine seen in kindled mice raises the possibility that kindling induces changes in the endogenous opiate systems of these animals.

The convulsions induced by morphine may be dependent on the establishment of an epileptic focus by kindling. Evidence in support of this position include the observation that morphine induced convulsions are very similar to those displayed during kindling and the report that morphine produced electroencephalographic spiking in the amygdala [8]. It might be argued that kindled animals have already been shown to have an increased sensitivity to many different convulsant agents such as lidocaine [35] and metrazol [32]. The significant point here is that morphine is not normally a convulsant for C57 mice as we have shown that it generally requires lethal doses to produce convulsions in these animals and even then the convulsions are qualitatively very different than those produced following kindling.

The time dependent decline in the morphine effects observed in our experiment may seem to be inconsistent with the generally accepted idea that kindled rats exhibit clonic convulsions upon the first stimulation even months after the termination of the kindling regimen. In actuality, however, kindled rats left unstimulated for 12 weeks required an average of 4 stimulations before observing a generalized (stage 5) convulsion [19]. We tested, therefore, the permanence of kindling in those mice in the 90 days group that had not exhibited convulsions when tested with morphine. These animals required an average of 4.3 stimulations before showing the first stage 5 convulsion. The results, therefore, are in close agreement with the earlier data from rats and suggest that some aspect of kindling delines with time. This decline appears to be due to local changes at the electrode tip, because most of the animals progressed immediately to a stage 5 convulsion after showing little or no afterdischarge following several preceding stimulations. Two additional daily stimulations produced generalized (stage 5-7) convulsions. When tested a second time with morphine 3 days later, all animals had clonic convulsions. These additional results suggest that the increase in morphine sensitivity parallels the persistence of the kindling effect.

Although the electrodes in the present study were localized in the amygdala, apparently convulsions do not have to be triggered from a temporal lobe structure, as mice undergoing motor cortex kindling also show a heightened sensitivity to morphine when tested 3 days after their last convulsion. Recent work in our laboratory has shown that mice kindled in the anterior cortex also showed a higher incidence of clonic convulsions and an exaggerated Straub tail response when tested with morphine $(25 \mathrm{mg} / \mathrm{kg})$.

While the long-lasting effects produced by kindling have been demonstrated in tests with morphine and can be blocked by pretreatment with naloxone, it is certainly possible that other neural systems are actually undergoing the changes. The biogenic amines, for example, have been shown to suppress seizures $[2,9,10,13,27,37,40]$ and kindling in turn has been shown to alter all of the amines as well as other neurotransmitters $[5,14,15,18,30,31]$. Moreover, kindling has been shown recently to produce long-lasting decreases in response to such catecholamine agonists as amphetamine [12] and cocaine [35]. Without ad- 
ditional work, it is not possible to decide among alternative hypotheses as the endogenous opiate systems activated by morphine are believed to modulate activity of the biogenic amines $[7,21,23,26]$.

\section{ACKNOWLEDGEMENTS}

We wish to thank Guy Mittleman for statistical advice and Buda Martonyi for technical assistance. This work was supported by NIMH Grant 1R03-MH 35615-01.

\section{REFERENCES}

1. Adamec, R. Behavioral and epileptic determinants of predatory attack behavior in the cat. Can. J. Neurol. Sci. 2: 456-466, 1975.

2. Arnold, P. S., R. J. Racine and R. A. Wise. Effects of atropine, reserpine, 6-hydroxydopamine, and handling on seizure development in the rat. Expl Neurol. 40: 457-470, 1973.

3. Belenky, G. L., V. E. Bates and J. W. Holaday. Effects of chronic heat exposure on opiate challenge and the opiate-like effects of electroconvulsive shock in rats. Soc. Neurosci. Abstr., 1980.

4. Belenky, G. L. and J. W. Holaday. Electroconvulsive shock (ECS) in rats: Naloxone modification of post ECS behaviors provides evidence for functional endorphin release. In: Endogenous and Exogenous Opiate Agonists and Antagonists, edited by E. L. Way. New York: Pergamon Press, 1979, pp. 487-490.

5. Burchfiel, J. L., M. S. Duchowny and F. H. Duffy. Neuronal supersensitivity to acetylcholine induced by kindling in the rat hippocampus. Science 204: 1096-1098, 1979.

6. Castellano, C. and A. Oliverio. A genetic analysis of morphine induced running and analgesia in the mouse. Psychopharmacologia 41: 197-200, 1975.

7. Celsen, B. and K. Kutchinsky. Effects of morphine on kinetics of $\mathrm{C}^{14}$ dopamine in rat striatal slices. Archs Pharmac. 284: 159 $165,1974$.

8. Chou, D. T. and S. C. Wong. Unit activity of amygdala and hippocampal neurons: Effects of morphine and benzodiazepine. Brain Res. 126: 427-440, 1977.

9. Corcoran, M. E., H. C. Fibiger, J. A. McCaughran and J. A. Wada. Potentiation of amygdaloid kindling and metrozolinduced seizures by 6 hydroxydopamine. Expl Neurol. 45: 118133,1974

10. Corcoran, M. E. and S. T. Mason. Role of forebrain catecholamines in amygdaloid kindling. Brain Res. 190: 473-484, 1980.

11. Corcoran, M. E. and J. A. Wada. Naloxone and kindling of seizures. Life Sci. 24: 791-796, 1979.

12. Ehlers, C. L., G. F. Koob, S. L. Henriksen and F. E. Bloom. Changes in locomotor activity in rats kindled in the amygdala and nucleus accumbens septi. Soc. Neurosci. Abstr., 1980.

13. Engel, J. and R. Katzman. Facilitation of amygdaloid kindling by lesions of the stria terminalis. Brain Res. 122: 137-142, 1977.

14. Engel, J. and N. S. Sharpless. Long lasting depletion of dopamine in the rat amygdala by kindling stimulation. Brain Res. 136: 381-386, 1977.

15. Farjo, I. B. and D. H. R. Blackwood. Reduction in tyrosine hydroxylase activity in the rat amygdala induced by kindling stimulation. Brain Res. 153: 423-426, 1978.

16. Frenk, H., B. C. McCarty and J. C. Liebeskind. Different brain areas mediate the anlgesic and epileptic properties of enkephalin. Science 200: 335-336, 1978.

17. Frenk, H. G. Urca and J. C. Liebeskind. Epileptic properties of leucine and methianine-enkephalin: Comparison with morphine and reversibility by naloxone. Brain Res. 147: 327-337, 1978.

18. Gee, K. W., M. A. Hollinger, J. F. Bowyer and E. K. Killam. Modification of dopaminergic receptor sensitivity in rat brain after amygdaloid kindling. Expl Neurol. 66: 771-777, 1979.

19. Goddard, G., D. McIntyre and C. A. Leech. A permanent change in brain function resulting from daily electrical stimulation. Expl Neurol. 25: 295-330, 1969.

20. Hardy, C., J. Panksepp, J. Rossi and A. J. Zolovick. Naloxone facilitates amygdaloid kindling in rats. Brain Res. 194: 293-297, 1980.
21. Henderson, G. and J. Hughes. The effects of morphine on the release of noradrenaline from mouse vas deferens. Br. J. Pharmac. 57: 551-557, 1976.

22. Hong, J. S., P. L. Wood, J. C. Gillin, H. Y. T. Ynag and E. Costa. Changes of hippocampal met-enkephalin content after recurrent motor seizures. Nature 285: 231-232, 1980.

23. Korf, J., B. S. Bunney and G. K. Aghajonian. Noradrenergic neurons: Morphine inhibition of spontaneous activity. Eur. $J$. Pharmac. 25: 165-169, 1974.

24. Le Gal La Salle, G., B. Calvino and Y. Ben-Ari. Morphine enhances amygdaloid seizures and increases interictal spike frequency in kindled rats. Neurosci. Lett. 6: 255-260, 1977.

25. Le Gal La Salle, G. and J. Lapouska. Amygdaloid kindling procedure reduces severity of morphine withdrawal syndrome in rats. Brain Res. 184: 239-242, 1980.

26. Loh, H. H., D. A. Brase, S. Sanpati-Khanna, J. B. Mar, E. L. Way and C. H. Li. Beta-endorphin in vitro inhibition of striatal dopamine release. Nature 260: 267-268, 1976.

27. Maynert, E. W. The role of biochemical and neurochemical factors in the laboratory evaluation of the antiepileptic drugs. Epilepsia 10: 145-162, 1969.

28. McIntyre, D. C. Effects of focal vs. generalized kindled convulsions from anterior neocortex or amygdala on CER acquisition in rats. Physiol. Behav. 23: 855-859, 1979.

29. McIntyre, D. C., M. Saari and B. A. Pappas. Potentiation of amygdala kindling in adult or infant rats by injections of 6 hydroxydopamine. Expl Neurol. 63: 527-544, 1979.

30. McNamara, J. O. Muscarinic cholinergic receptors participate in the kindling model of epilepsy. Brain Res. 154: 415-420, 1978.

31. McNamara, J. O. Selective alterations of regional B-adrenergic receptor binding in the kindling model of epilepsy. Exp/ Neurol. 61: $582-591,1978$.

32. Pinel, J. P. J. and K. F. Cheung. Controlled demonstration of metrazol kindling. Pharmac. Biochem. Behav. 6: 599-600, 1977.

33. Pinel, J. P. J., D. Triet and L. I. Rovner. Temporal lobe aggression in rats. Science 197: 1088-1089, 1977.

34. Post, R. M., S. Davenport, A. Pert and K. M. Squillace. Lack of effect of an opiate agonist and antagonist on the development of kindling in the rat. Communs Psychopharmac. 3: 185-190, 1979.

35. Post, R. M., K. M. Squillace, A. Pert and W. Sass. The effect of amygdala kindling on spontaneous and cocaine-induced motor activity and lidocaine seizures. Psychopharmacology 72: 189196, 1981

36. Racine, R. J. Modification of seizure activity by electrical stimulation: II. Motor seizures. Electroenceph. clin. Neurophysiol. 32: 281-284, 1972.

37. Racine, R. J. and D. V. Coscina. Effects of midbrain raphe lesions or systemic p-chlorophenylalamine on the development of kindled seizures in rats. Brain Res. Bull. 4: 1-7, 1979.

38. Simantov, R., M. Kuhar, G. Uhl and S. Snyder. Opioid peptide enkephalin: Immunohistochemical mapping in rat central nervous system. Proc, natn. Acad. Sci, U.S.A. 74: 2167-2171, 1977.

39. Teitelbaum, H., J. Blossen and G. Catravas. Bilateral electroencephalographic response and unilateral tolerance to unilateral intracerebral morphine injections. Nature 260: 158-159, 1976.

40. Wilkison, D. M. and L. M. Halpern. Role of biogenic amines in amygdalar kindling. I. Local amygdalar afterdischarge. $J$. Pharmac. exp. Ther. 211: 151-158, 1979. 